\title{
Spinal, Cerebral and Cerebellar Embolism after Injection of N-Butyl-2-Cyanoacrylate in Esophageal Variceal Bleeding
}

\author{
Jun Hee Bang, Seung Jae Jang, Young Gon Jung, Jong In Choi, Chang Kook Park, Ho Dong Kim \\ Department of Internal Medicine, St. Carollo Hospital, Suncheon, Korea
}

\begin{abstract}
We report a case of spinal, cerebral and cerebellar embolism that occurred following injection sclerotherapy with n-butyl-2-cyanoacrylate for variceal bleeding. The patient had been diagnosed with alcoholic liver cirrhosis and esophageal variceal bleeding. We performed injection sclerotherapy with n-butyl-2-cyanoacrylate. The patient complained of both leg motor weakness and left arm motor weakness after injection and was diagnosed with spinal, cerebral and cerebellar embolism following the n-butyl-2-cyanoacrylate injection. At the follow-up examination, the patient's neurologic symptoms had improved, but left leg motor weakness remained. To our knowledge, this is the first report of a case of multiple embolizations including the spine, cerebrum and cerebellum after n-butyl-2-cyanoacrylate injection for treatment of esophageal variceal bleeding. (Korean J Helicobacter Up Gastrointest Res 2016;16:103-106)
\end{abstract}

Key Words: Spinal embolism; N-butyl-2-cyanoacrylate, Bleeding

\section{INTRODUCTION}

Esophageal varices are abnormal, enlarged veins in the esophagus. Esophageal varices occur most often in people with liver cirrhosis. The varices may leak blood or even rupture, causing life-threatening bleeding. Variceal bleeding accounts for approximately one fifth to one third of all deaths in liver cirrhosis patients. A number of medical procedures can help prevent and stop bleeding from esophageal varices. Currently, endoscopic treatment remains the predominant method for the prevention and treatment of variceal bleeding. Endoscopic treatments include band ligation and injection sclerotherapy. Although endoscopic injection of n-butyl-2-cyanoacrylate (Histoacryl; B-Braun Surgical GmbH, Melsungen, Germany) has been reported to be an effective therapy for variceal bleeding, but Histoacryl injection is associated with serious complications, some of which can be disastrous. ${ }^{1}$

We present a case of spinal, cerebral and cerebellar embolism after injection of Histoacryl in esophageal variceal bleeding. To our knowledge, this is the first report of

Received: February 10, 2016 Accepted: April 18, 2016

Corresponding author: Ho Dong Kim

Department of Internal Medicine, St. Carollo Hospital, 221 Sungwang-ro, Suncheon 57931, Korea

Tel: +82-61-720-2127, Fax: +82-61-720-6159, E-mail: raphael65@hanmail.net a case of multiple embolizations including the spine, cerebrum and cerebellum after Histoacryl injection in esophageal variceal bleeding.

\section{CASE REPORT}

A 45-year-old man, suffering from liver cirrhosis secondary to alcohol (Child-Pugh class C) was admitted for hematemesis and melena. He had a history of esophageal variceal bleeding in the year 2009, 2012, 2013, and 2014. We performed esophaegal variceal band ligations. On admission, he had a pulse of 90 beats/min, a blood pressure of $80 / 50 \mathrm{mmHg}$, and a respiratory rate of 30 breaths $/ \mathrm{min}$. The head and neck examination was normal, except for anemic conjunctiva. The abdomen was nontender with ascites. Laboratory studies revealed the following: hemoglobin $8.0 \mathrm{~g} / \mathrm{dL}$ (normal range, 12 18 g/dL), hematocrit

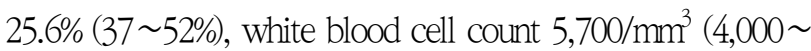
$\left.10,800 / \mathrm{mm}^{3}\right)$, platelet count $121,000 / \mathrm{mm}^{3}(130,000 \sim$ $\left.450,000 / \mathrm{mm}^{3}\right)$, total protein $5.9 \mathrm{~g} / \mathrm{dL}(5.8 \sim 8.1 \mathrm{~g} / \mathrm{dL})$, albumin $2.9 \mathrm{~g} / \mathrm{dL}(3.1 \sim 5.2 \mathrm{~g} / \mathrm{dL})$, total bilirubin $1.31 \mathrm{mg} / \mathrm{dL}$ (0.3 1.3 mg/dL), AST $40 \mathrm{U} / \mathrm{L}(7 \sim 38 \mathrm{U} / \mathrm{L})$, and ALT $23 \mathrm{U} / \mathrm{L}$ (6 42 U/L). His coagulation profiles were prothrombin time $16.3 \mathrm{sec}(11 \sim 14.9 \mathrm{sec})$ and activeated partial thromboplastin time $36.3 \mathrm{~s}$ (28 40 sec). Endoscopy was performed. Varices were identified, with extensive fibrosis in

Copyright $\odot 2016$ Korean College of Helicobacter and Upper Gastrointestinal Research

(.) The Korean Journal of Helicobacter and Upper Gastrointestinal Research is an Open-Access Journal. All articles are distributed under the terms of the Creative Commons Attribution Non-Commercial License (http://creativecommons.org/licenses/by-nc/4.0) which permits unrestricted non-commercial use, distribution, and reproduction in any medium, provided the original work is properly cited. 
the surrounding area because of previous banding sessions (Fig. 1A). We decided to do esophaegal variceal band ligation (EVL). The device was pointed toward bleeding point and placed with continuous suction to draw the target lesion into the cap (Fig. 1B). But the target lesion was not sucked into the cap. After several attempts to suck, bleeding was activated. Jet of blood from an esophageal varix appeared (Fig. 1C). After all, we performed injection sclerotherapy with a mixture of Histoacryl and Lipiodol (Laboratoire Guerbet, Aulnay-Sous-Bois, France). The mixture consisted of $0.5 \mathrm{~mL}$ of Histoacryl and $0.8 \mathrm{~mL}$ of Lipiodol. The mixture was injected intra-variceally using a 21-gauge needle injector. Because variceal bleeding was not controlled after the first and second injection, the third injection was performed in the same manner. After the third injection, variceal bleeding was controlled (Fig. 1D). The total injected volume was $3.9 \mathrm{~mL}$. However, he developed both leg motor weakness (grade I/V) 4 hours after the injection. Magnetic resonance imaging (MRI) of the spine showed no definite increased signal in T-spinal cord on T2 weighted images. But MRI of the spine showed multiple increased signals in T-spinal cord on diffusion image.
Noncontrasted computed tomography (CT) scan of the spine showing multiple small hyperdense foci between C7-T1, T1-T2, T2-3 and in T2 left paravertebral, T6 body level (Fig. 2A). His family wanted to take him to another hospital at night. He came back from another hospital next day. He developed left arm motor weakness when he was back. Noncontrasted CT scan of the brain showed multifocal hypodense areas in both cerebral hemispheres, suggesting infarcts and multiple tiny radioopaque densities in left cerebral hemispheres (Fig. 2B). Follow up MRI of the spine and cerebellum showed high signals in cerebellum on diffusion image (Fig. 3), in C2 level, and in T-spinal cord from T3 to T10 levels on T2 weighted images (Fig. 4).

To evaluate the cause of the newly developed embolism, a transcranial Doppler (TCD) bubble test was performed. The TCD bubble test is used to detect a right- to-left shunt. We used $2 \mathrm{MHz}$ M-mode TCD (SONARA; Viasys Healthcare, Conshohocken, PA, USA) to detect microbubbles in the middle cerebral artery. TCD did not demonstrate the presence of a microbubble on the M-mode displays in the middle cerebral artery. TCD was negative. Contrasted transthoracic echocardiogram (TTE) was per-
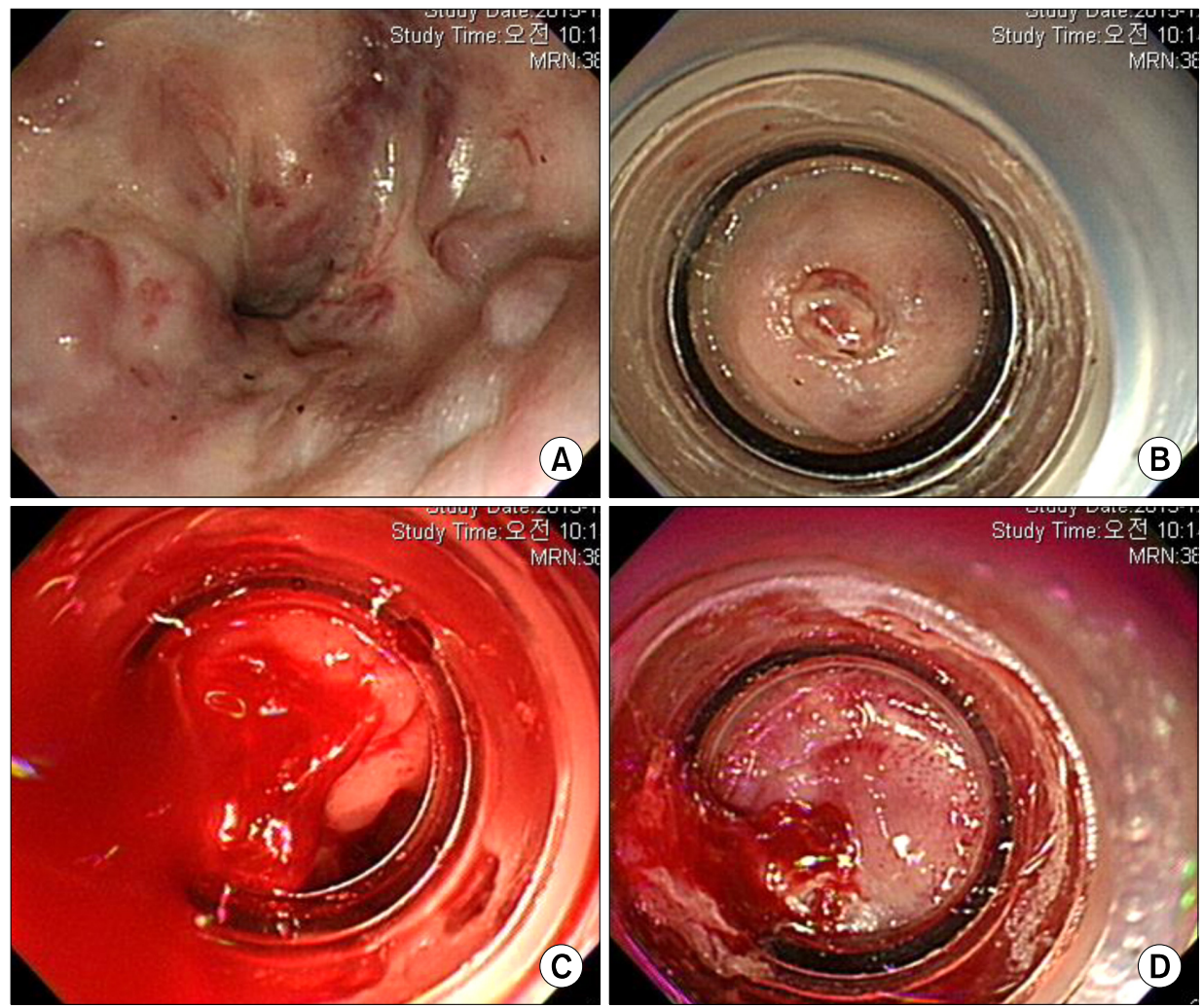

Fig. 1. Endoscopic findings showed venous engorgements in lower esophagus (A, B), jet of blood from an esophageal varix $(\mathrm{C})$ and histoacryl matetial (D) 

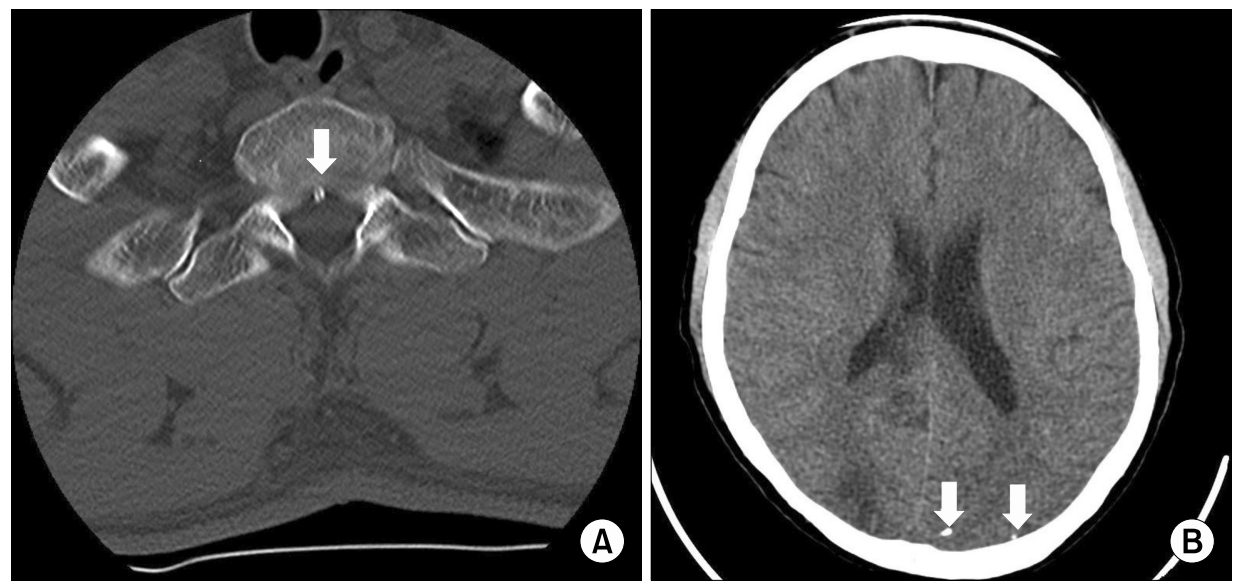

Fig. 2. (A) Non-contrast spine and (B) brain computed tomography showed multiple high attenuation lesions (arrows). The multiple high attenuation lesions were emboli of the Histoacryl-Lipiodol mixture.
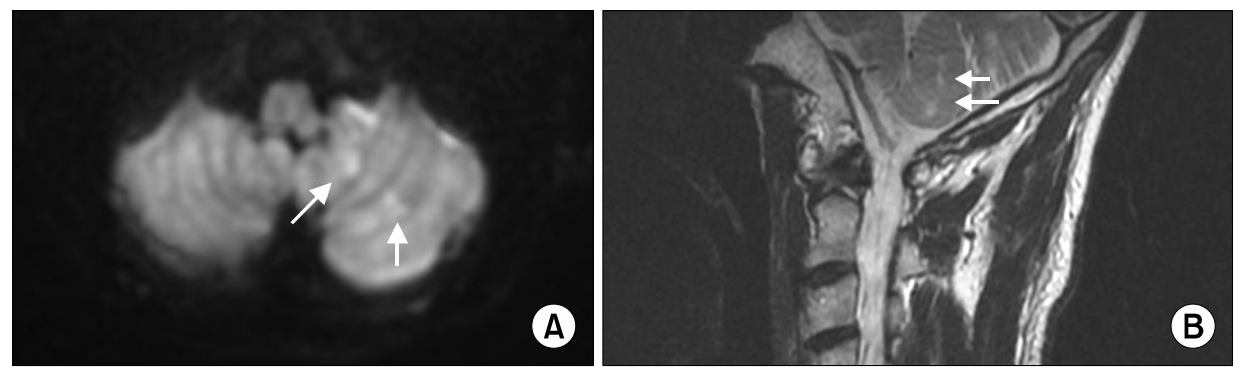

Fig. 3. MRI of cerebellum showed high signals (arrows) on (A) diffusion image and (B) T2 weighted images.

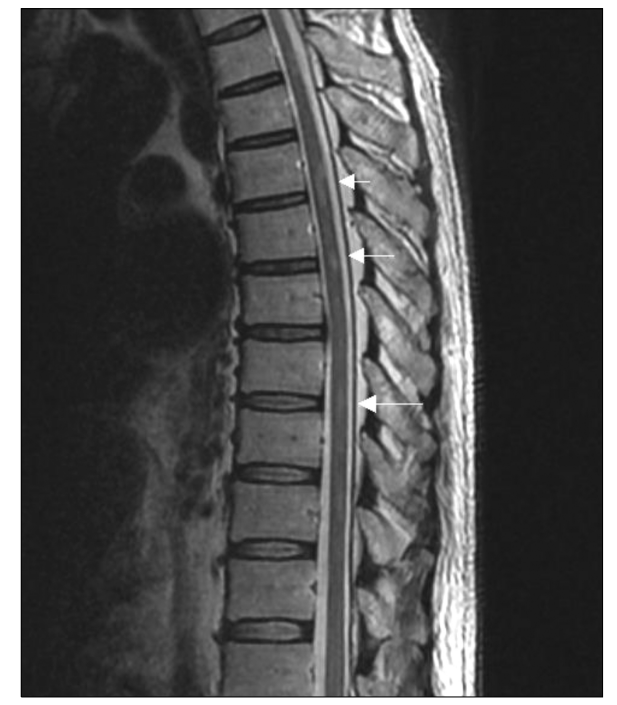

Fig. 4. MRI of spine showed high signals (arrows) on T2 weighted images.

formed to demonstrate patent foramen ovale. But TTE showed no abnormality as well. TCD and TTE showed no evidence of right-to-left shunt.

At the follow-up examination after 4 weeks, his neurologic symptoms were improved, but left leg motor weakness remained.

\section{DISCUSSION}

Portal hypertension causes the development of portosystemic collaterals, among which esophageal and gastric varices are the most relevant. ${ }^{2}$ After initial diagnosis of cirrhosis, the expected incidence of newly developed varices is about $5 \%$ per year. ${ }^{3,4}$ Varices rupture can result in hemorrhage, which is one of the most lethal complications of portal hypertension.

Traditionally, esophageal varices are treated with EVL and/or sclerotherapy. EVL has proven more beneficial especially versus the traditional (and now outdated) sclerosant agents such as alcohol and ethanolamine. However, newer agents like 'cyanoacrylate' glue injection therapy have quickly shown benefit in the management of esophageal and gastric varices. ${ }^{5}$ To date, there has been limited data assessing the role of glue therapy in the treatment of esophageal variceal bleeding. The largest series and most convincing evidence comes from a prospective study of 133 consecutive cirrhotic esophageal variceal bleeding patients treated by intravariceal glue injection. ${ }^{6}$ A validated alternative is glue injection therapy (especially if a 
restricted luminal size (e.g., paediatric cases) and/or multiple pre-existing bands/banding ulcers proves technically challenging; with glue injection therapy effective in cases of refractory esophageal variceal bleeding despite prior recent intervention). ${ }^{5}$

EVL should be regarded as the endoscopic technique of choice in the treatment of esophageal varices. ${ }^{7}$ The mucosa and submucosa of the esophagus are ensnared, leading to strangulation, sloughing, and eventual fibrosis -ideally with obliteration of the varices after previous EVL. However, it may be difficult to suction adequate tissue into the banding cap for relatively small esophageal varix or previously treated varix. In our patient, the esophageal varix was not sucked into the cap due to fibrosis. We performed injection sclerotherapy with Histoacryl. Spinal, cerebral and cerebellar embolism followed the esophageal variceal injection sclerotherapy.

The possible explanation for the development of systemic emboli may be the transient patent foramen ovale caused by the episodes of coughing, which induced a temporary right-to left shunt. Clearly, transesophageal echocardiography (TEE) is considered the gold standard for right-to-left shunt diagnosis, but it is poorly tolerated by patients and sometimes requires sedation. ${ }^{8}$ We performed a TCD bubble test and TTE rather than TEE. The TCD bubble test has proven to be a trustworthy and less invasive method for diagnosing a right-to-left shunt. ${ }^{9}$ But TCD and TTE showed no evidence of intracardiac shunt. Therefore, we do not know how systemic embolization in our case occur. However, other authors presumed that the paradoxical embolization occurred via an arteriovenous pulmonary shunt. ${ }^{10,11}$

Factors that increase embolization risk include the size of varices, the presence of a collateral vessel, excessive dilution, rapid polymerization, large volume $(>1 \mathrm{~mL} / \mathrm{in}-$ jection) and rapid Histoacryl injection. ${ }^{12}$ Our case had the two possible embolic risk factors including the large volume $(>1 \mathrm{~mL})$ of the mixture injected, and dilution.

Systemic embolization including the cerebrum, lung, spleen, adrenal, and portal vein is a rare and serious complication of Histoacryl injection that has been principally described in the treatment of variceal bleeding. ${ }^{13}$ Systemic embolization should be considered for the treat- ment of esophageal variceal bleeding with Histoacryl. Ours is the first report of a case of multiple embolizations including the spinal, cerebral and cerebellar after the esophageal variceal injection of Histoacryl.

\section{REFERENCES}

1. Schuman BM, Beckman JW, Tedesco FJ, Griffin JW Jr, Assad RT. Complications of endoscopic injection sclerotherapy: a review. Am J Gastroenterol 1987;82:823-830.

2. Poza Cordon J, Froilan Torres C, Burgos García A, Gea Rodriguez F, Suárez de Parga JM. Endoscopic management of esophageal varices. World J Gastrointest Endosc 2012;4:312-322.

3. Merli M, Nicolini G, Angeloni S, et al. Incidence and natural history of small esophageal varices in cirrhotic patients. J Hepatol 2003;38:266-272.

4. de Franchis R, Dellera A, Fazzini L, Zatelli S, Savojardo V, Primignani M. Evaluation and follow-up of patients with portal hypertension and oesophageal varices: how and when. Dig Liver Dis 2001;33:643-646.

5. El Sayed G, Tarff S, O'Beirne J, Wright G. Endoscopy management algorithms: role of cyanoacrylate glue injection and self-expanding metal stents in acute variceal haemorrhage. Frontline Gastroenterol 2015;6:208-216.

6. Cipolletta L, Zambelli A, Bianco MA, et al. Acrylate glue injection for acutely bleeding oesophageal varices: a prospective cohort study. Dig Liver Dis 2009;41:729-734.

7. Krige JE, Shaw JM, Bornman PC. The evolving role of endoscopic treatment for bleeding esophageal varices. World J Surg 2005;29:966-973.

8. Myung DS, Chung CY, Park HC, et al. Cerebral and splenic infarctions after injection of N-butyl-2-cyanoacrylate in esophageal variceal bleeding. World J Gastroenterol 2013;19:57595762.

9. Sarkar S, Ghosh S, Ghosh SK, Collier A. Role of transcranial Doppler ultrasonography in stroke. Postgrad Med J 2007;83: 683-689.

10. Yu LK, Hsu CW, Tseng JH, Liu NJ, Sheen IS. Splenic infarction complicated by splenic artery occlusion after N-butyl-2-cyanoacrylate injection for gastric varices: case report. Gastrointest Endosc 2005;61:343-345.

11. Martins Santos MM, Correia LP, Rodrigues RA, Lenz Tolentino LH, Ferrari AP, Della Libera E. Splenic artery embolization and infarction after cyanoacrylate injection for esophageal varices. Gastrointest Endosc 2007;65:1088-1090.

12. Matsumoto A, Takimoto K, Inokuchi H. Prevention of systemic embolization associated with treatment of gastric fundal varices. Mayo Clin Proc 2005;80:705.

13. Lee BY, Jang JY, Jeong SW, et al. Two cases of adrenal abscesses following histoacryl $\mathrm{R}$ (N-butyl-2-cyanocrylate) injection. Gut Liver 2011;5:242-244. 